\title{
The canopy rainfall interception in actual and potential distribution of Qinghai spruce (Picea crassifolia) forest
}

\author{
Zhonglin $\mathrm{Xu}{ }^{1,2,3, *}$, Zhaodong Feng ${ }^{1,2,4}$, Chuanyan Zhao ${ }^{5}$, Jianghua Zheng ${ }^{1,2,3}$, Jianjun Yang ${ }^{1,2}$, \\ Fengxia Tian ${ }^{6}$, Huanhua Peng ${ }^{4}$, Chao Wang ${ }^{4}$, Shouzhang Peng ${ }^{3}$, Hassan Sher ${ }^{7}$ \\ ${ }^{1}$ MOE Key Laboratory of Oasis Ecology, Xinjiang University, Urumqi 830002, China. \\ ${ }^{2}$ College of Resource \& Environmental Science, Xinjiang University, Urumqi 830002, China. \\ ${ }^{3}$ Key Laboratory of City Intellectualizing and Environment Modelling, Xinjiang University, Urumqi 830002, China. \\ ${ }^{4}$ College of Earth and Environmental Sciences, Lanzhou University, Lanzhou 730000, China. \\ ${ }^{5}$ MOE Key Laboratory of Arid and Grassland Agroecology, Lanzhou University, Lanzhou 730000, China. \\ ${ }^{6}$ Institute of Mountain Hazards and Environment, Chinese Academy of Sciences, Chengdu 610041, China. \\ ${ }^{7}$ Centre of Botany \& Biodiversity Conservation, University of Swat, Khyber Pakhtunkhwa, 19130 Saidu Sharif, District Swat, Pakistan. \\ * Corresponding author. Tel.: +8618999195490. E-mail: galinwa@gmail.com
}

\begin{abstract}
Interception is one of the most underestimated processes in hydrological cycle in arid and semiarid regions. In Qilian Mountains of northwestern arid and semiarid China, the Qinghai spruce (Picea crassifolia) forest plays an important role in the hydrological cycle of the inland Heihe River basin. The historical disturbance of Qinghai spruce forest has resulted in various ecological problems. In order to realize the sustainable development of Heihe River basin, the Chinese government implemented restoration practices for Qinghai spruce in the past three decades. In this study, we estimated the rainfall interception in the actual and potential distribution of Qinghai spruce forest. Some of the important findings include: (1) The interception ratio of rainfall events ranged from 11-51\% with a mean value of $27.02 \%$; (2) Totally, $147 \mathrm{Mt}$ of rainfall is intercepted by canopy of actual Qinghai spruce forest, in the projected potential distribution of the forest, totally $407 \mathrm{Mt}$ of rainfall will be intercepted.
\end{abstract}

Keywords: Qinghai spruce; Actual interception; Potential interception; Potential distribution; Ecohydrology.

\section{INTRODUCTION}

Changes of structure and distribution of landscapes at different temporal and spatial scales may influence a series of ecohydrological processes such as surface runoff (Loren et al., 2010), infiltration (Hejduk and Kasprzak, 2010), water quality (Bhadhuri et al., 1997), soil erosion (Sánchez et al., 2002), solute cycling (Williams et al., 2004), etc. As a result, the cumulative effect of landscape changes on hydrological and ecological processes is always the focus of environmental scientists (Cosandey et al., 2005). The forest, due to its important ecological and hydrological functions in terrestrial ecosystems, have been increasingly concerned mainly on the environmental effects of its extraction in arid and semiarid regions where forest represents a major natural and economic resource (Domingo et al., 1998). To better manage the forest resource, basic information on the effect of forest extraction on environment need to be understood. At arid and semiarid regions, the water relations of forest are of major interest at river basin scale where extraction of forest may affect water yield through regulating the rainfall interception (Smettem et al., 2006; Holko, 2010). During a rain event, some drops fall through the forest canopy directly to the ground while others are intercepted by forest canopy, water that remains on the vegetation and is evaporated during or after rainfall events is described as interception; water that may or may not contact the canopy and falls to the ground is measured as throughfall; water that flows to the ground via trunks and stems is measured at as stemflow (Crockford and Richardson, 2000).

Distributed at upper reach of Heihe River basin (the second largest inland river basin in the arid and semiarid regions of northwestern China), the Qinghai spruce (Picea crassifolia) forest plays an important role in the hydrological cycle of the
Heihe River basin, but the forest experienced extensive deforestation during long disturbance of human since Han Dynasty ( $\sim 200$ B.C.) to 1980 's, the deforestation has induced various socio-economical and eco-environmental problems (Wang et al., 2002). In order to restore the deteriorated environment, and to accomplish the sustainable development in the whole Heihe River basin, Qilian Mountains National Nature Reserve was established and some afforestation and reforestation practices were conducted since 1986, the Qinghai spruce forest was recovered to a certain extent, but according to an estimation of deforested area of Qinghai spruce, there still $60 \%$ of Qinghai spruce has the potential to reestablish (Xu et al., 2011). It can be expected that these afforestation and reforestation practices may result in large area of recovered spruce forest, but how these recovered forest may influence the hydrological cycle of Heihe River basin is still not clear, so the one aim of this paper is to demonstrate a regional modelling approach to predict the rainfall interception of Qinghai spruce forest in its projected potential distribution. The other aim of the present study is discuss the possibility of the application of plant species potential distribution on hydrological cycling at regional scale, literature reviewing demonstrated that there still exist no report focusing on such topic.

\section{MATERIALS AND METHODS 2.1 Study area}

The study was conducted at the Qilian Mountains National Nature Reserve (Fig. 1). Warm and humid summers, cold and dry winters characterize the region's climate. Mean annual rainfall is about $550 \mathrm{~mm}$ at southeast portion and less than 200 $\mathrm{mm}$ at northwest portion of the study area, $90 \%$ of the annual rainfall occurring between May and October. Snow accounts 
for less than $1 \%$ of the annual rainfall. The mean annual air temperature is $\sim 6^{\circ} \mathrm{C}$ at the lowlands and is $-10^{\circ} \mathrm{C}$ at the highest elevations. The mean annual rainfall and mean annual temperature have a decreasing trend from the southeast to the north- west. The vegetation types in the Qilian Mountains include, from low to high elevations, desert, desert steppe, forest-steppe, sub-alpine shrubby meadow, alpine frost-action barren zone, and the permanent snow and ice.

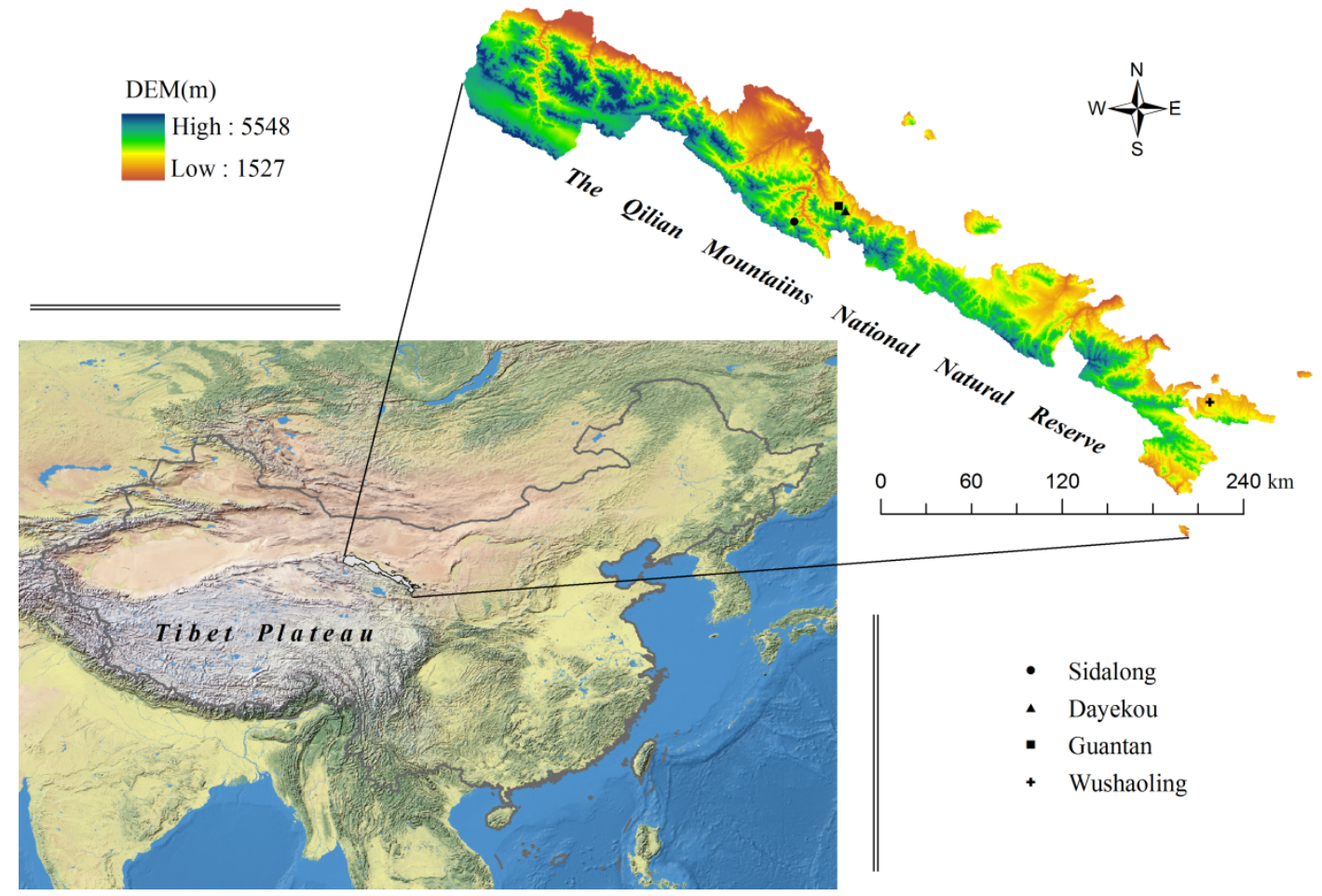

Fig. 1. The location of study area.

\subsection{Data}

Two sets of data were collected: (1) the one related to the actual and potential distribution of Qinghai spruce. The actual distribution of study species was provided by Forest Inventory and Planning Institute of Gansu Province. The data were compiled using remotely sensed data and the accuracy of the data was later validated through intensive and extensive field investigations. The potential distribution of Qinghai spruce was modeled through species distribution modeling, nineteen climatic layers (annual trends, extremes and seasonality of temperature and rainfall, see Hijmans et al., 2005) and two waterenergy layers (topographic wetness index and total annual solar radiation, derived from Digital Elevation Model) were collected before the modeling, it should be noted that during species distribution modeling, the presence samples (and absence samples in some cases, depending on the modeling methods) is also needed, so we also collected 93 presence and 33 absence samples of Qinghai spruce during our field investigation at Aug., 2008; (2) The other related to canopy interception estimation in the spruce forest, specifically, they are leaf area index (LAI, an important structural property of plant canopy, namely the onesided leaf area per unit ground area, essential in calculating terrestrial energy, carbon, water-cycle processes, and biogeochemistry of vegetation) and rainfall events (including the corresponding canopy interception).

Since our aim was to estimate the interception at regional scale, so we firstly established the regression relationship between LAI and interception at plot scale, then applied this relationship at regional scale (the Qilian Mountains National Na- ture Reserve) to accomplish our aim. Because we cannot measure the LAI at each point within the Reserve, so in this paper, the relationship between measured LAI (at sampling point) and the satellite derived LAI (covered the whole study area) was also established. The measured LAI was obtained using LICOR LAI-2000, as denoted by $\mathrm{LAI}_{L A I-2000}$. The satellite derived LAI, MOD15 LAI ( $\left.\mathrm{LAI}_{M O D I S}\right)$, is a product of Moderate Resolution Imaging Spectroradiometer (MODIS) Terra and was downloaded from LPDAAC (2001). The rainfall events and corresponding canopy interception were collected during our field investigations conducted at Dayekou (May-Oct., 2008), Guantan (May-Oct., 2009), Sidalong (May-Oct., 2011) and Wushaoling (May-Oct,. 2009). These four sites were selected since long-term meteorological data are available. At each site, a plot with a wide range of openness was set up in order to obtain the canopy interception. The area of plot for Dayekou, Guantan, Sidalong and Wushaoling was $400 \mathrm{~m}^{2}, 400 \mathrm{~m}^{2}, 900$ $\mathrm{m}^{2}$ and $900 \mathrm{~m}^{2}$, respectively. Not far away from these plots, an automatic weather station was installed.

\subsection{Field measurements}

\subsubsection{Event rainfall}

Event rainfall was measured in all of the four study sites using automatic weather station with a resolution of $0.1 \mathrm{~mm}$ to provide information on the number and duration of individual rainfall events in the open space. The rainfall events were classified as separate event if the time between events exceeded 5 $\mathrm{h}$, and the duration of rainfall was determined as the number of rain-hours in a rainfall event. 


\subsubsection{Throughfall and interception}

Throughfall was measured on all of the raining days between May and October, which are growing season for Qinghai spruce (Zhang et al., 2010). We used plastic round bucket $(0.2 \mathrm{~m}$ in diameter) to collected the throughfall, these bucket were regularly (3 $\mathrm{m}$ interval within the plots of Sidalong and Wushaoling) or randomly (within the plot of Dayekou and Guantan) located within these plots. The buckets were kept in the same positions throughout May to October to assess the relationship between canopy structure and spatial variability of the throughfall. Interception was calculated as the difference between the amount of rainfall that was actually collected in the buckets and the amount that was measured by the automatic weather station.

\subsubsection{Field measurement of LAI}

The LAI-2000 instrument has an optical sensor which consists of five light sensors arranged in concentric rings spanning the zenith angles $0-13^{\circ}, 16-28^{\circ}, 32-43^{\circ}, 47-58^{\circ}$, and $61-74^{\circ}$. It measures radiation in the blue spectrum $(320-490 \mathrm{~nm})$, where scattering from leaves is low (Welles and Norman, 1991). Performed at the same time as rainfall events, measurements were acquired at sunset or on overcast days Given the fact that LAI2000 may detect objects or gaps outside of small plots, so in order to reduce the influence of the adjacent plots and of the operator, a $45^{\circ}$ view-cap was applied on the optics (Welles and Norman, 1991; LI-COR, Inc., Lincoln, NE, 1992). We recorded readings both in the forest plots (above the plastic round buckets) and simultaneously in an open area in the forest. The number of buckets were 90, 20, 90 and 89 within the plot of Dayekou, Guantan, Sidalong and Wushaoling, respectively, as a results, totally 289 LAI values were recorded (Fig. 2). The standard LAI-2000 outputs (five rings, 5R) were reprocessed using the LI-COR C2000 software.

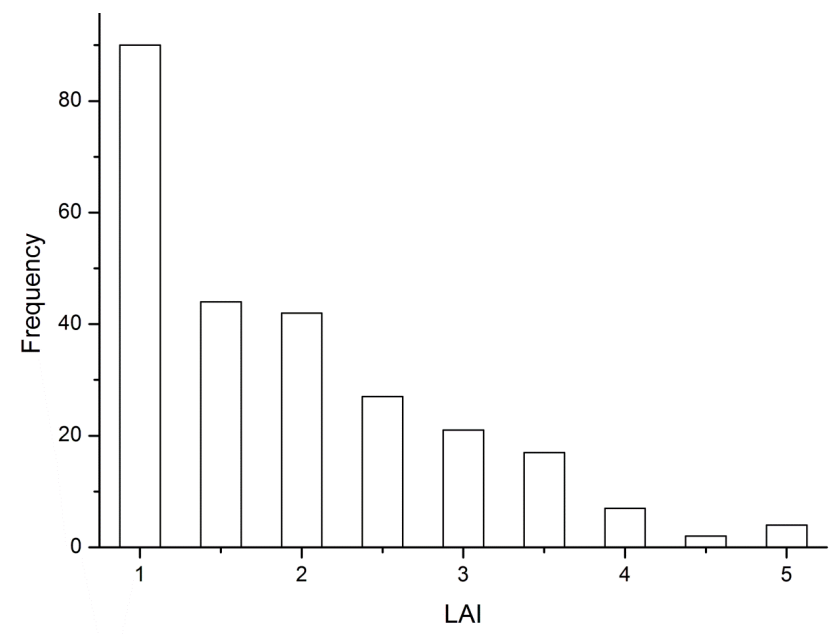

Fig. 2. The frequency of the LAI in four study plots.

\subsection{Interception estimation}

As mentioned above, the plastic round buckets were used to collect the throughfall at four study plot, within the plot of Dayekou, Guantan, Sidalong and Wushaoling, there were 90, 20, 90 and 89 buckets, respectively. For the rainfall, 33 events at Dayekou, 24 at Guantan, 35 at Sidalong and 30 at Wushaoling, totally 122 rainfall events were recorded during May to October at four study sites. We did not observe any throughfall when the gross rainfall was less than $1.5 \mathrm{~mm}$, this means 12 rainfall (3 at Dayekou, 5 at Guantan, 3 at Sidalong and 1 at Wushaoling) events were not suitable to be used to find relationship between rainfall and interception, so these 12 rainfall events were excluded.

So far, for each of the study plot, we have LAI values which were necessary to depict the canopy structure, observed rainfall events and related "effective" interception. It should be noted that the LAI value could be seemed as a constant throughout a single growing season, but the interception could not be a constant percent of rainfall for different rainfall event. So all of the interception corresponded to different rainfall events should be used to establish the relationship between rainfall and interception. Take the plot of Dayekou as an example, 90 LAI values were obtained, consequently, 90 interception data can be recorded after each rainfall event. When considering all the number of events (i.e., 30), totally $2700(90 \times 30)$ groups of data (each group consists of LAI, gross rainfall and interception) could be obtained. For the other three sites (i.e., Guantan, Sidalong and Wushaoling), the number of effective data groups is 380,2880 and 2581 , respectively. In order to obtain confident relationship between interception, rainfall and LAI, all the observed data at four study sites should be used, which means totally 8542 groups of data are available for the regression and validation of the related relationship.

Several models have been developed to make predictions of interception based on rainfall and canopy characteristics. These models have been based largely on either the Rutter (Rutter et al., 1971) or Gash (Gash, 1979) models. The following model was considered to be physically based, and was developed to provide insight into the interception process and be able to compute the interception of annual rainfall (Blake, 1975):

$$
I=S\left(1-\exp \left(-\frac{P}{C}\right)\right)+E
$$

where $I$ is the intercepted rainfall, $S$ is the maximum canopy storage capacity, $P$ is the gross rainfall, $C$ is an empirical coefficient related to canopy storage and $E$ is the evaporation from the canopy. Peng et al. (2010) derived a similar equation during their research works related to the interception loss of Qinghai spruce as follows:

$$
I=I_{c m}^{*} \cdot L A I \cdot\left(1-\exp \left(-\frac{P}{I_{c m}^{*} \cdot L A I}\right)\right)+a \cdot P
$$

where $I_{c m}^{*}$ and $a$ are regression coefficient. Here, $5125(60 \%$ of 8542) groups of observed data were used to quantify the regression coefficient $I_{c m}^{*}$ and $a$, the regression result was 0.45 and 0.27 for $I_{c m}^{*}$ and $a$, respectively, the other $40 \%$ (3417) groups were used to test the acceptability of the two coefficients.

The interception estimated use Eq. (2) was actually the interception of single rainfall event and on the plot scale, whereas our objective was to estimate the mean annual interception at regional scale, this means Eq. (2) was not suitable for the estimation of annual interception. Compare with the relatively easer accessibility of spatial distribution LAI, the characteristics of event rainfall (including the depth, the duration and number of events) at each pixel within the study area cannot be confidently obtained. So we analyzed the relationship between LAI 
and interception ratio (the event interception divided by event rainfall), and established relationship between LAI and average interception ratio, specifically, for a given LAI level, we computed how much rainfall (average interception ratio) was intercepted (Table 1 and Fig. 3). Then we extracted the LAI of the pixels where has been distributed by Qinghai spruce, and average interception ratio corresponding to the specific LAI level was assigned to the pixels, finally, by applying the average interception ratio to the annual rainfall, the annual interception can be estimated.

The interception in the potential distribution area of Qinghai spruce was estimated by the same strategies, it should be noted that at those areas where the Qinghai spruce actually not but predicted to be distributed, the LAI value extracted from $\mathrm{LAI}_{M O D I S}$ were not the reasonable value because the surface coverings were predicted to be replaced by Qinghai spruce forest and the LAI value might not be the value at present, so during the estimation of interception at these area, the average value of LAI of actual distribution of Qinghai spruce forest was used.

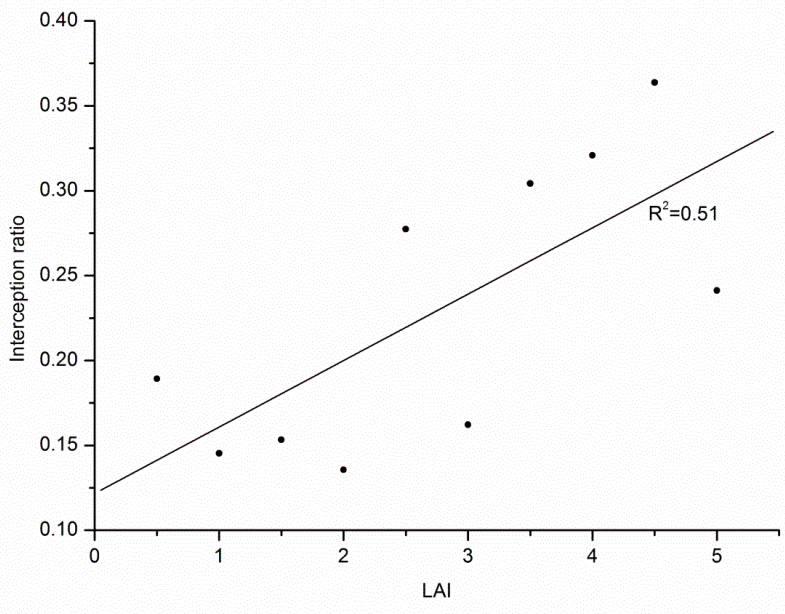

Fig. 3. The relationship between LAI and interception ratio.

Table 1. The relationship between LAI and average annual interception ratio.

\begin{tabular}{lllllllllll}
\hline LAI & $0.0-0.5$ & $0.5-1.0$ & $1.0-1.5$ & $1.5-2.0$ & $2.0-2.5$ & $2.5-3.0$ & $3.0-3.5$ & $3.5-4.0$ & $4.0-4.5$ & $4.5-5.0$ \\
\hline $\begin{array}{l}\text { Interception } \\
\text { ratio (\%) }\end{array}$ & 24.12 & 36.37 & 32.08 & 30.42 & 16.22 & 27.73 & 13.56 & 15.33 & 14.53 & 18.92 \\
\hline
\end{tabular}

\subsection{The potential distribution modeling of Qinghai spruce}

We used Maximum Entropy Species Distribution Modeling ver. 3.3.3 (hereafter, Maxent; Phillips et al., 2006; Phillips and Dudik, 2008) to construct maximum entropy models for Qinghai spruce. Maximum entropy approaches rely on presenceonly data to model the distributions of species. The Maxent approach has been shown to have high predictive performance relative to other presence-only approaches (Elith et al., 2006). Advantages of Maxent include: (1) It requires only presence samples of species; (2) It can employ both categorical and continuous data; (3) It converges well to the optimum (maximum) entropy; (4) The Maxent probability distribution has a mathematical definition; (5) Over-fitting can be prevented. Maxent estimates habitat favorability (as probability of presence) on a landscape according to observed presence points of species and the values of gridded environmental variables from files with equal pixel size and spatial extent. We ran Maxent with default parameters and the model produced a continuous output of habitat suitability values that range from 0 to 1 , where 0 is least suitable, and 1 is most suitable (Phillips et al. 2006).

In order to produce a final distribution map with binary values ( 1 for predicted presence and 0 for predicted absence), a threshold value need to be determined, and the value was determined through constructing a presence-absence confusion matrix or error matrix (Fielding and Bell, 1997). The error matrix was composed of 4 elements denoted by $a, b, c$ and $d$. Where: $a$ expresses true positive (recorded present, predicted present), $b$ is false positive (recorded absent, predicted present), $c$ false negative (recorded present, predicted absent) and $d$ true negative (recorded absent, predicted absent); $a$ and $d$ are correct classifications; $b$ represents omission error and $c$ commission error. The threshold value was then determined through three sensitivity-specificity sum maximization (SSM) approach (Jiménez-Valverde and Lobo, 2006). Our moving-search of the threshold values indicates that the threshold is 0.225 for SSM.
To serve the threshold searching purpose, we field surveyed 93 presence sites representing 93 pixels and 33 absence sites representing 33 pixels.

\section{RESULTS AND DISCUSSIONS 3.1 Validation of the Eq. (2)}

As mentioned before, $60 \%$ of observed data were used to regress the coefficient in Eq. (2), and $40 \%$ were used to test the acceptability of the two coefficients, so we compared the value of interception modeled by Eq. (2) and observed during field work, the comparison was achieved through computing the mean absolute error (MAE), which is given by Eq. (3), where $m_{i}$ is the modeled value and $o_{i}$ the observed value. We also computed the determination of coefficient $\left(\mathrm{R}^{2}\right)$ to measure how well the observed values are likely to be predicted by the Eq. (2). The corresponding calculation and Fig. 4 revealed that the mean absolute error and the determination of coefficient $\left(\mathrm{R}^{2}\right)$ was 3.29 and $0.69(\mathrm{p}<0.01)$, respectively.

$M A E=\frac{1}{n} \sum_{i=1}^{n}\left|m_{i}-o_{i}\right|=\frac{1}{n} \sum_{i=1}^{n}\left|e_{i}\right|$

\subsection{The response of interception to $\mathrm{LAI}$ and event rainfall}

The LAI ranged from 0.1 to 4.8 in the Qinghai spruce forest as shows in Fig. 2, the values are consistent with that of reported by Zhao et al. (2009) as 1.0-3.7. Since the throughfall cannot be observed when the event rainfall is less than $1.5 \mathrm{~mm}$, so the rainfall events with lesser depth were excluded for the establishment of relationship between event rainfall and interception. It can also be found that the rainfall events with more than $32 \mathrm{~mm}$ of depth are rare (Peng et al., 2010), so these events were also excluded. The response surface of the interception to LAI and event rainfall is clearly reflected in Fig. 5: (1) the 
interception ranged from $0.1-7.6 \mathrm{~mm}$ depends on the LAI and event rainfall, generally, the interception is positively correlated to LAI and event rainfall, with the increase of LAI and event rainfall from lower-left to upper-right corner, the interception also increased. (2) For a specific LAI, the more interception was observed at those areas with more annual rainfall, it is obvious that more rainfall may result in more water that could be intercepted by forest canopy, Komatsu et al. (2008) also reported similar pattern. For a given depth of rainfall, the more interception could be found at those areas with larger LAI. The increased interception may depend on the increase in leaf amounts, as shown in the relationship between interception and LAI that has been reported elsewhere (e.g., Park, 2000; Komatsu et al., 2008). (3) The lower-right corner in Fig. 5 denotes the interception at those areas with higher LAI during small rainfall event, the dense isoline demonstrate that during these event, the relatively more water is needed to saturate the canopy of Qinghai spruce due to the more leaf amounts.

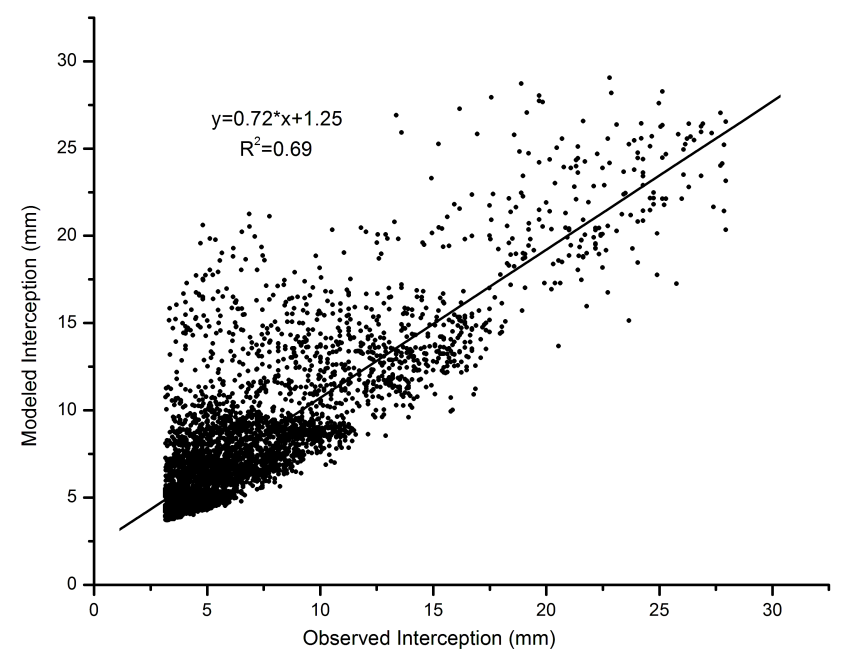

Fig. 4. The relationship between observed interception and modeled interception of event rainfall.

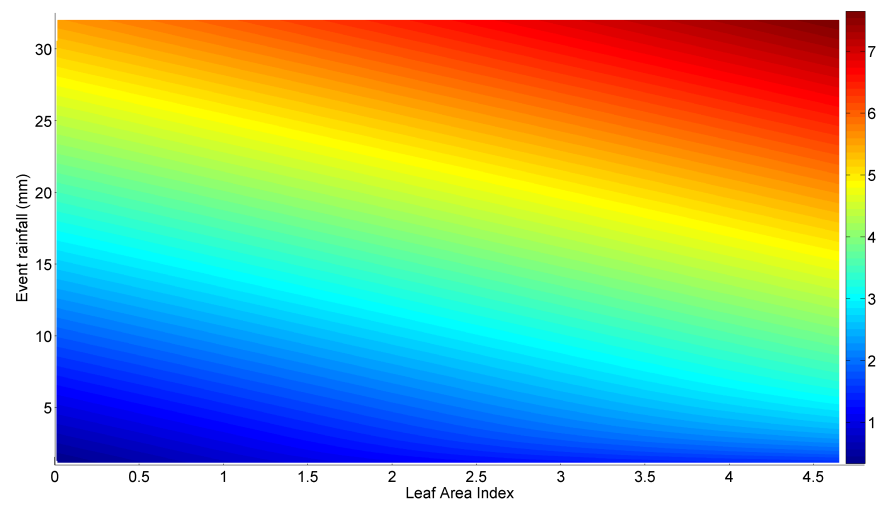

Fig. 5. The response surface of the interception to LAI and event rainfall. The horizontal and vertical axis denote the gradient of LAI and event rainfall (mm), the interception (from low to high) is displays as colors from bluish to redish.

We calculated the interception ratio of rainfall events in the Qinghai spruce forest, the ratio ranged from $11-51 \%$ with a mean value of $27.02 \%$, which is comparable to literature, i.e.,
Llorens et al. (1997) reported 15-49\% interception by conifers in a Mediterranean mountainous area. The similar result was also obtained during the interception loss study which was conducted at boreal forest at Siberian (Toba and Ohta, 2005). In this study, the interception ratio converged to $\sim 20 \%$ when the depth of rainfall reaches $20 \mathrm{~mm}$, the same results has been displayed in Crockford and Richardson (2000), where for the pine plantation, the interception ratio reaches $\sim 20 \%$ when the rainfall exceeds $20 \mathrm{~mm}$, but for Eucalypt forest, the ratio converged to $\sim 10 \%$ when the rainfall exceeds $\sim 12 \mathrm{~mm}$, the difference was allocated to the impact of discontinuity (dry gaps) on interception. Although the constant ratio also existed in the pine and larch forest in Siberia and pine and oak forest in Japan, but the ratio (i.e., 20\%) can only be observed when the rainfall reaches $40 \mathrm{~mm}$, and regardless the forest structure and climate, as reported by Toba and Ohta (2005).

\subsection{The regional estimation of interception 3.3.1 The validation of the estimation strategy}

As mentioned before, since the characteristics of event rainfall (including the depth, the duration and the number of events) at each pixel within the study area cannot be confidently obtained, estimating the mean annual interception through summing up all the event rainfall interception is impossible, as a result, we constructed the relationship between specific LAI level (i.e., $A_{i}$ ) and average interception ratio (i.e., $a_{i} \%$ ) as shown in Table 1 , and assuming that totally $a_{i} \%$ of annual rainfall is intercepted for a given LAI. The rationality of the assuming is that when construct the correspondence relationship, the average interception ratio was obtained based on observed interception data, and furthermore, different depths of rainfall events were included. We also validated the estimation strategy through comparing the measured and estimated interception as shows in Table 2 and Fig. 6, where the gross rainfall between May to October was measured during filed works, the actual interception was recorded use the methods mentioned before (i.e., section 2.3.2), the estimated interception was obtained by applying the average interception ratio to the measured gross rainfall. The validation was achieved by computing the MAE and coefficient of determination between measured and estimated interception, the corresponding result was $9.8 \mathrm{~mm}$ and 0.53 for MAE and $\mathrm{R}^{2}$, respectively.

\subsubsection{The actual interception}

Total annual rainfall in the study area ranged from $99 \mathrm{~mm}$ to $576 \mathrm{~mm}$ as shows in Fig. 7, relatively larger annual rainfall was observed at southeast part of the study area, and the annual rainfall decreasing from southeast to northwest. We calculated the total annual rainfall which falls above the Qinghai spruce forest and the corresponding calculation gives us a totally of $488 \mathrm{Mt}$. In order to estimate the actual interception, we firstly assigned the interception ratio to each pixel which distributed by Qinghai spruce, the interception ratio was based on the constructed relationship between interception ratio and LAI. Then cooperated the annual rainfall with corresponding interception ratio, the total rainfall that could be intercepted by canopy of Qinghai spruce forest can be estimated. Subsequently, by sum up the interception at each pixel, the total actual interception could be calculated. Such strategies gives us a totally $147 \mathrm{Mt}$ of rainfall that could be intercepted by canopy of Qinghai spruce forest. Divide the $147 \mathrm{Mt}$ of intercepted water by the total rainfall of $488 \mathrm{Mt}$, the total interception ratio of $30.12 \%$ at the entire study area was obtained. 
Table 2. The observed and estimated interception characteristics at four study sites.

\begin{tabular}{lccccc}
\hline Study sites & $\begin{array}{c}\text { Gross rainfall (mm, May } \\
\text { to October) }\end{array}$ & $\begin{array}{c}\text { Actual interception } \\
(\mathrm{mm})\end{array}$ & $\begin{array}{c}\text { Actual interception } \\
\text { ratio (\%) }\end{array}$ & $\begin{array}{c}\text { Estimated intercep- } \\
\text { tion (mm) }\end{array}$ & $\begin{array}{c}\text { Estimated interception } \\
\text { ratio (\%) }\end{array}$ \\
\hline Dayekou & 353.7 & 91.7 & 25.93 & 90.9 & 25.70 \\
Guantan & 321.3 & 76.1 & 23.68 & 91.4 & 29.45 \\
Sidalong & 336.6 & 101.0 & 30.00 & 92.6 & 27.51 \\
Wushaoling & 387.6 & 110.3 & 28.46 & 125.1 & 32.28 \\
\hline
\end{tabular}

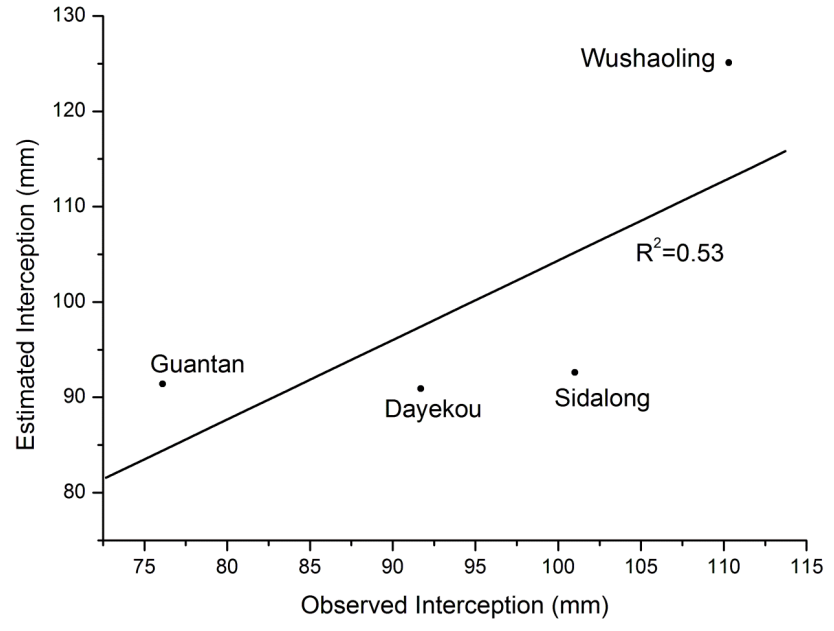

Fig. 6. The relationship between observed interception and modeled interception of annual rainfall at four study plots.

\subsubsection{The potential distribution of Qinghai spruce}

Based on Maxent model and environmental variables (nineteen climate layers from worldclim data set, topographic wetness index and annual solar radiation), the potential distribution of $P$. crassifolia in Qilian Mountains was estimated. Compare the potential distribution with the actual distribution revealed that almost $60 \%$ of Qinghai spruce has been deforested. At northwest part of the study area, the potential distribution is similar with actual distribution. The most severe disturbance was actually occurred at middle and southeast portion of the study area, at middle part of the study area, nearly $70 \%$ of the Qinghai spruce forest has been deforested. At southeast part, the actual distribution account for less than $50 \%$ of potential distribution (Xu et al., 2011). Zhao et al. (2010) reported that the forest land has been transformed to farmland and grassland at these two part of the study area.

\subsubsection{The potential interception}

The aforementioned relationship between the annual interception and the independent variables (i.e., annual rainfall and LAI) are now ready to be applied to quantification of mean annual interception in the potential distribution Qinghai spruce forests. Specifically, annual rainfall was a layer (i.e., layer 12) from worldclim data set, the LAI, as mentioned before (i.e., section 2.4), need to be reassigned at those potential (actually not distributed but predicted to be suitable for study species) distribution areas of Qinghai spruce, the $\mathrm{LAI}_{M O D I S}$ value were actually not the reasonable value because the surface coverings were predicted to be replaced by Qinghai spruce forest and the LAI value may change, so during the estimation of interception in the actually not but predicted to be distributed areas of Qinghai spruce, the average value of LAI of actual distribution of Qinghai spruce forest was used. Similar to the estimation of actual interception, we firstly assigned the interception ratio to each pixel. Then cooperated the annual rainfall with corresponding interception ratio, the total rainfall that could be intercepted by canopy of Qinghai spruce forest can be estimated. Finally, by sum up the interception at each pixel, the total actu-

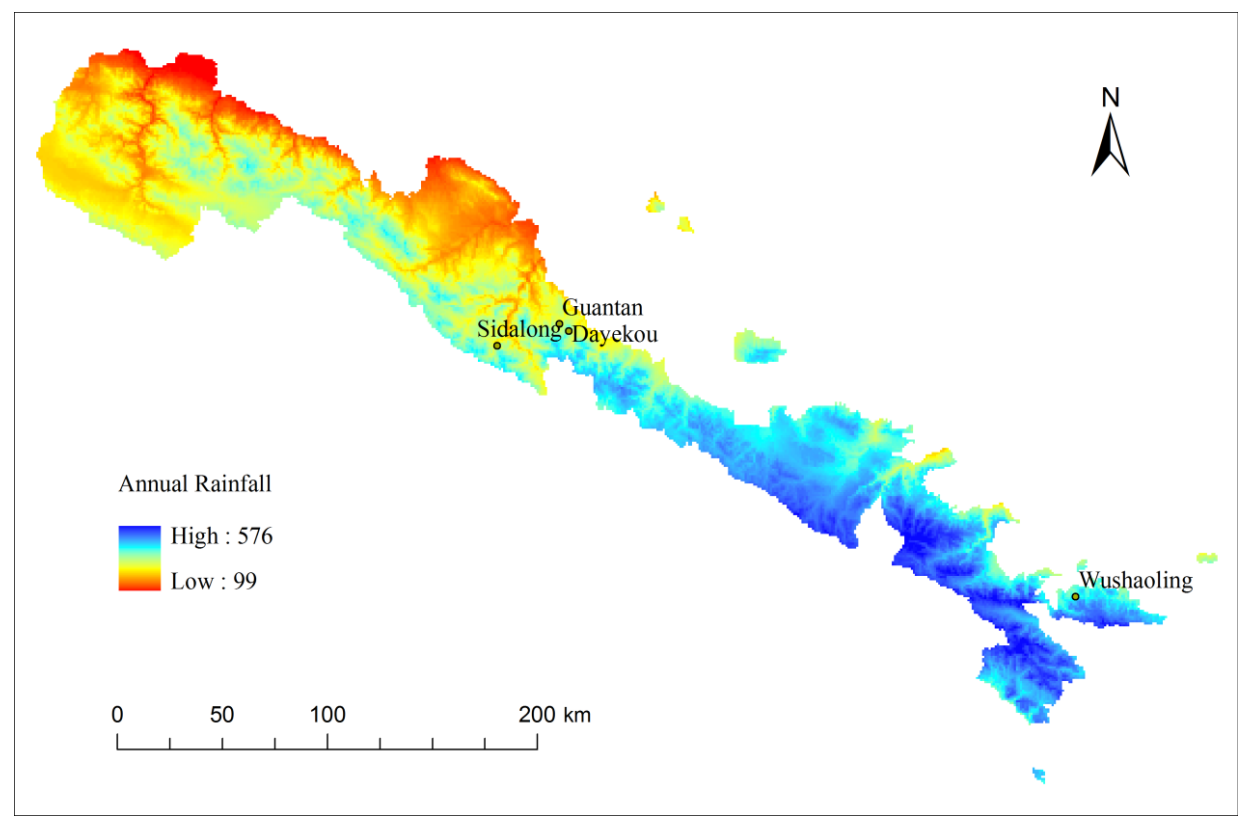

Fig. 7. The annual rainfall in the study area. 
al interception al could be calculated. Such estimation gives us a totally $407 \mathrm{Mt}$ of rainfall that might be intercepted by canopy of Qinghai spruce forest. Divide the $1332 \mathrm{Mt}$ of intercepted water by the total rainfall of $488 \mathrm{Mt}$ (at the actual and potential distribution area of Qinghai spruce), the total interception ratio of $30.56 \%$ at the entire study area can be obtained.

\subsection{Source of uncertainty}

\subsubsection{Stem flow}

The stem flow was commonly being considered account for only a small proportion of the rainfall, and some time was not measured (Crockford and Richardson, 2000; Dunkerley, 2000; Link et al., 2004), but large variation in stem flow was also reported. As to the coniferous forest, the large variation of proportion of stem flow to rainfall warrant special care. For the Sitka spruce, $12.6 \%$ of rainfall reaching the ground as stem flow (Anderson and Pyatt, 1985), during an interception study conducted at Pinus Pinaster forest, the stem flow was measured to be $1 \%$ of rainfall (Gash et al., 1995). Li et al. (2006) reported that the stem flow accounted only $0.07 \%$ of rainfall in Abies faxoniana forest. In this study, we neglected the stem flow when estimating the canopy interception at Qilian Mountains, but the literature related to stem flow of Qinghai spruce suggest that the neglect may cause variation in the amount of water that could be intercepted by canopy of spruce forest. For example, Chang et al. (2002) reported that the stem flow account for $0.51 \%$ of rainfall and the stem flow can be observed only when rainfall is larger than $12 \mathrm{~mm}$, but Dang et al. (2005) argued that the stem flow account for less than $0.1 \%$ of the rainfall. Based on totally 83 rainfall events and related investigation, Zhang et al. (2007) demonstrated in their research that the stem flow may reaches 2.24\% with respect of rainfall in Qinghai spruce forest, and the stem flow happens when the depth of rainfall event reaches $13.60 \mathrm{~mm}$.

\subsubsection{Cloud interception}

A large canopy surface area can intercept a substantial fraction of rainfall, reducing the volume of water that falls directly to the ground, correspondingly, a large canopy surface also increases leaf area available for cloud interception (Holder, 2004). In both the presence and absence of rainfall, cloud interception can increase throughfall not only through direct addition of water to canopy surface but also by reducing evaporation from the canopy; when fog is present, high relative humidity and decreased solar radiation reduce evaporative demand (Eugster et al., 2006; Ritter et al., 2008). Predicting the extent and significance of cloud interception is difficult because weather and forest structure have varying effects on forest hydrologic processes (Baruman et al., 2010). In the present study, we did not considered the cloud interception, but according to Bruijnzeel and Hamilton (2000), cloud interception may increases throughfall to $80-100 \%$ of rainfall, so the cloud interception need to be studied in the future in order to reliably estimate the contribution of forest canopy on the hydrological processes.

\subsubsection{The annual and growing season rainfall}

As mentioned before, the rainfall and interception data used in this study were collected during growing season of Qinghai spruce, which is actually from May to October, then based on the relationship between LAI and interception ratio, we esti- mated the annual interception by applying the interception ratio to annual rainfall, in doing this, the snow interception during winter was actually replaced directly by rainfall interception, although the rainfall during growing season (i.e., May to October) account for $90 \%$ of annual rainfall, such treatment was still problematic and may introduce another uncertainty of the present study. As reported by Zhang et al. (2007), averagely $49.1 \%$ of the snowfall could be intercepted by forest canopy, but how much of the intercepted snow could be sublimated was still unclear. Pomeroy and Schmidt (1993) reported that in boreal forest, $\sim 30 \%$ of snowfall could be sublimated. The similar result (30\% of intercepted snow was sublimated) was also confirmed in boreal forest canopies (Pascal and Dennis, 2002) and sub-alpine forest (Molotch et al., 2007). In the present study, uncertainty might be induced by applying the interception ratio (which is related to LAI, ranged from $11-51 \%$ with average of $27.02 \%$ ) to annual rainfall, in doing so, the sublimation ratio was actually displaced by interception ratio during snowfall event in winter.

\section{CONCLUSIONS}

In the present study, we firstly predicted the potential distribution of Qinghai spruce forest, we then estimated the actual and potential canopy rainfall interception in the actual and potential distribution of the forest. Some of the conclusions are: (1) The interception ratio of rainfall events ranged from 11$-51 \%$ with a mean value of $27.02 \%$; (2) Totally, $147 \mathrm{Mt}$ of rainfall is intercepted by canopy of actual Qinghai spruce forest, the correlated interception ratio is $30.12 \%$. In the projected potential distribution of the forest, totally 407 of rainfall will be intercepted and the interception ratio is $30.56 \%$. (3) The relatively coarse resolution during the potential distribution modelling of Qinghai spruce may introduced uncertainties, as a results, we suggest fine resolution need to be considered in the future plant potential distribution modelling related to hydrological applications.

Acknowledgement. This project was supported by Nation Natural Science Foundation of China (No. 91025015, No. 41201032, No. 41271168, No. 51269030); The Yangtse Rive Scholar and Initiative Research Group Development Program (Ministry of Education, China, No. IRT1180). This manuscript was also improved from communications with Lubomir Lichner and two anonymous referees.

\section{REFERENCES}

Anderson, A.R., Pyatt, D.G., 1985. Interception of precipitation by pole-stage Sitka spruce and lodgepole pine and mature Sitka spruce at Kielder forest, Northumberland. Forestry, 59, 1, 29-38.

Bhadhuri, B., Grove, M., Lowry, C., Harbor, J., 1997. Assessing long term hydrologic effects of land use change. J. Am. Water. Works. Ass., 89, 11, 94-106.

Blake, G.J., 1975. The Interception Process. Australian Academy of Science, Canberra.

Brauman, K.A., Freyberg, D.L., Daily, G.C., 2010. Forest structure influences on rainfall partitioning and cloud interception: A comparison of native forest sites in Kona, Hawai'i. Agr. Forest. Meteorol., 150, 2, 265-275.

Bruijnzeel, L.A., Hamilton, L.S., 2000. Decision Time for Cloud Forests. UNESCO, Paris. 
Chang, X.X., Zhao, A.F., Wang, J.Y., Chang, Z.Q., Jin, B.W., 2002. Precipitation characteristic and interception of forest in Qilian Mountain. Plateau Meteorology, 21, 3, 274-280. (In Chinese with English abstract.)

Cosandey, C., Andréassian, V., Martin, C., Didon-Lescot, J.F., Lavabre, J., Folton, N., Mathys, N., Richard, D., 2005. The hydrological impact of the Mediterranean forest: a review of French research. J. Hydrol., 301, 1-4, 235-249.

Crockford, R.H., Richardson, D.P., 2000. Partitioning of rainfall into throughfall, stemflow and interception: effect of forest type, ground cover and climate. Hydrol. Process., 14, 16-17, 2903-2920.

Dang, H.Z., Zhou, Z.F., Zhao, Y.S., 2005. Study on forest interception of Picea crassifolia. Journal of Soil and Water Conservation, 19, 4, 60-64. (In Chinese with English abstract.)

Domingo, F., Sánchez, G., Moro, M.J., Brenner, A.J., Puigdefábregas, J., 1998. Measurement and modelling of rainfall interception by three semi-arid canopies. Agr. Forest. Meteorol., 91, 275-292.

Dunkerley, D., 2000. Measuring interception loss and canopy storage in dryland vegetation: a brief review and evaluation of available research strategies. Hydrol. Process., 14, 4, 229 -278 .

Elith, J., Graham, C.H., Anderson, R.P., Dudík, M., Ferrier, S., Guisan, A., Hijmans, R.J., Huettmann, F., Leathwick, J.R., Lehmann, A., Li, J., Lohmann, L.G., Loiselle, B.A., Manion, G., Moritz, C., Nakamura, M., Nakazawa, Y., McOverton, J. C., Peterson, A.T., Phillips, S.J., Richardson, K.S., ScachettiPereira, R., Schapire, R.E., Soberón, J., Williams, S., Wisz, M.S., Zimmermann, N.E., 2006. Novel methods improve prediction of species' distribution from occurrence data. Ecography, 29, 2, 129-151.

Eugster, W., Burkard, R., Holwerda, F., Scatena, F.N., Bruijnzeel, L.A.S., 2006. Characteristics of fog and fogwater fluxes in a Puerto Rican elfin cloud forest. Agr. Forest. Meteorol., 139, 3-4, 288-306.

Fielding, A.H., Bell, J.F., 1997. A review of methods for the assessment of prediction errors in conservation presence/absence models. Environ. Conserv., 24, 1, 38-49.

Gash, J.H.C., 1979. An analytical model of rainfall interception by forest. Q. J. Roy. Meteor. Soc., 105, 43-45.

Gash, J.H.C., Lloyd, C.R., Lachaud, G., 1995. Estimating sparse forest rainfall interception with an analytical model. J. Hydrol., 170, 1-4, 79-86.

Hejduk, S., Kasprzak, K., 2010. Specific features of water infiltration into soil with different management in winter and early spring period. J. Hydrol. Hydromech., 58, 3, 175-180.

Hijmans R.J., Cameron S.E., Parra J.L., Jones P.G., Jarvis A., 2005. Very high resolution interpolated climate surfaces for global land areas. Int. J. Climatol., 25, 15, 1965-1978.

Holder, C.D., 2003. Fog precipitation in the Sierra de las Minas Biosphere Reserve, Guatemala. Hydrol. Process., 17, 10, 2001-2010.

Holko, L., 2010. Short-time measurements of interception in mountain spruce forest. J. Hydrol. Hydromech., 58, 4, 213 -220 .

Jiménez-Valverde, A., Lobo, J.M., 2006. The ghost of unbalanced species distribution data in geographical model predictions. Divers. Distrib., 12, 5, 521-524.

Link, T.E., Unsworth, M., Marks, D., 2004. The dynamics of rainfall interception by a seasonal temperature rainforest. Agr. Forest. Meteorol., 124, 171-191.

Komatsu, H., Shinohara, Y., Kume, T., Otsuki, K., 2008. Relationship between annual rainfall and interception ratio for forests across Japan. Forest. Ecol. Manag., 256, 5, 1189-1197 .

Llorens, P., Poch, R., Latron, J., Gallart, F., 1997. Rainfall interception by a Pinus sylvestris forest patch overgrown in a Mediterranean mountainous abandoned area I. Monitoring design and results down to the event scale. J. Hydrol., 199, 3-4, 331-345.

Loren, L.W., Frank, H.W., Thomas, F.C., 2010. Effect of land cover change on runoff curve number in Iowa, 1832-2001. Ecohydrol., 4, 2, 315-321.

LP DAAC, 2001. NASA Land Processes Distributed Active Archive Center. MOD 15 Leaf Area Index (LAI) and Fraction of Photosynthetically Active Radiation absorbed by vegetation (FPAR). USGS/Earth Resources Observation and Science (EROS) Center, Sioux Falls, South Dakota. 2001. http://lpdaac.usgs.gov/get_data.

Molotch, N.P., Blanken, P.D., Williams, M.W., Turnipseed, A.A., Monson, R.K., Margulis, S., 2007. Estimating sublimation of intercepted and sub-canopy snow using eddy covariance systems. Hydrol. Process., 21, 12, 1567-1575.

Park, H., Hattori, S., Kang, H., 2000. Seasonal and inter-plot variations of stemflow, throughfall and interception loss in two deciduous broad-leaved forests. Journal of Japan Society of Hydrology \& Water Resources, 13, 1, 17-30.

Pascal, S., Dennis, P.L., 2002. Measurement of snow interception and canopy effects on snow accumulation and melt in a mountainous maritime climate, Oregon, United States. Water. Resour. Res., 38, 11, 1-16.

Peng, H.H., Zhao, C.Y., Shen, W.H., Xu, Z.L., 2010. Modeling rainfall canopy interception of Picea crassifolia forest in northern slope of Qilian Mountains: a case of Pailugou catchment. Arid Land Geography, 33, 4, 600-606. (In Chinese with English abstract.)

Phillips, S.J., Anderson, R.P., Schapire, R.E., 2006. Maxent entropy modeling of species geographic distribution. Ecol. Model., 190, 3-4, 231-259.

Phillips, S.J., Dudík, M., 2008. Modeling of species distributions with Maxent: new extensions and a comprehensive evaluation. Ecography, 31, 2, 161-175.

Pomeroy, J.W., Schmidt, R.A., 1993. The use of fractal geometry in modelling intercepted snow accumulation and sublimation. Proceeding of Eastern Snow Conference, 50, 1-10.

Ritter, A., Regalado, C.M., Aschan, G., 2008. Fog water collection in a subtropical elfin laurel forest of the Garajonay National Park (Canary Islands): a combined approach using artificial fog catchers and a physically based impaction model. J. Hydrometeorol., 9, 5, 920-935.

Rutter, A.J., Kershaw, K.A., Robin, P.C., Morton, A.J., 1971. A predictive model of rainfall interception in forests I. Derivation of the model from observations in a plantation of corsican pine. Agr. Forest. Meteorol., 9, 367-384.

Sánchez, L.A., Ataroff, M., López, R., 2002. Soil erosion under different vegetation covers in the Venezuelan Andes. Environmentalist, 22, 1, 161-172.

Smettem, K.R., Harper, R.J., Watanabe, F., 2006. Can concepts of ecological optimality provide guidance for predicting the performance of replanted perennial vegetation in dryland areas? Journal of Arid Land Studies, 15, 4, 367-370.

Toba, T., Ohta, T., 2005. An observational study of the factors that influence interception loss in boreal and temperate forest. J. Hydrol., 313, 3-4, 208-220.

Wang, G.X., Cheng, G.D., Shen, Y.P., 2002. Features of ecoenvironmental changes in Hexi Corridor region in the last 50 years and comprehensive control strategies. Journal of Natu- 
ral Resources, 17, 1, 78-86. (In Chinese with English abstract.)

Welles, J., Norman, J., 1991. Instrument for indirect measurement of canopy architecture. Agron. J., 83, 5, 818-825.

Williams, M.R., Filoso, S., Lefebvre, P.A., 2004. Effects of land-use change on solute fluxes to floodplain lakes of the central Amazon. Biogeochemistry, 68, 2, 259-275.

Xu, Z.L., Zhao, C.Y., Feng, Z.D., 2012. Species distribution models to estimate the deforested area of Picea crassifolia in arid region recently protected: Qilian Mts. National Natural Reserve (China). Pol. J. Ecol., 60, 3, 515-524.

Zhang, X, Luo, L, Jing, W., Wang, S., Wang, R., Che, Z., 2007. Study on the distribution effect of canopy interception of Picea Crassifolia forest in Qilian Mountains. Journal of Mountain Science, 25, 6, 768-683. (In Chinese with English abstract.)
Zhang, Y.X., Wilmking, M., 2010. Divergent growth responses and increasing temperature limitation of Qinghai spruce growth along an elevation gradient at the northeast Tibet Plateau. Forest. Ecol. Manag., 260, 6, 1076-1082.

Zhao, C.Y., Shen, W.H., Peng, HH., 2009. Methods for determining canopy leaf area index of Qinghai spruce forest in Qilian Mountains, China. Chinese Journal of Plant Ecology, 33, 5, 860-869. (In Chinese with English abstract.)

Zhao, C.Y., Bie, Q., Peng, H.H., 2010. Analysis of the Niche Space of Picea crassifolia on the Northern Slope of Qilian Mountains. Acta Geographica Sinica, 65, 1, 113-121. (In Chinese with English abstract.)

Received 29 March 2012 Accepted 9 November 2012 